\title{
Modeling Human Glaucoma: Lessons from the in vitro Models
}

\author{
Inês Dinis Aires ${ }^{\mathrm{a}, \mathrm{b}}$ António Francisco Ambrósio ${ }^{\mathrm{a}-\mathrm{c}}$ Ana Raquel Santiago ${ }^{\mathrm{a}-\mathrm{c}}$ \\ ${ }^{a}$ Institute for Biomedical Imaging and Life Sciences (IBILI), Faculty of Medicine, and ${ }^{\mathrm{b}}$ CNC.IBILI Consortium, \\ University of Coimbra, and ' Association for Innovation and Biomedical Research on Light and Image (AIBILI), \\ Coimbra, Portugal
}

\section{Key Words}

Glaucoma · In vitro models · Elevated hydrostatic pressure .

Retinal ganglion cells

\begin{abstract}
Glaucoma, a leading cause of blindness worldwide, is a degenerative disease characterized by retinal ganglion cell (RGC) loss and optic nerve atrophy. Elevated intraocular pressure (IOP) is a main risk factor for onset and progression of the disease. Since increased IOP is the only modifiable risk factor, relevant models for glaucoma would comprise RGC and optic nerve damage triggered by ocular hypertension. Animal models of glaucoma have greatly contributed to the understanding of the molecular mechanisms of this pathology, and they have also facilitated the development of new pharmacological interventions. Although animal models of glaucoma have provided valuable information about the disease, there is still no ideal model for studying glaucoma due to its complexity. There is a recognized demand for in vitro models that can replace or reduce the need for animal experiments. Several in vitro models have emerged as a great opportunity in the field of glaucoma research, helping to clarify the mechanisms involved in disease progression. Several types of equipment have been developed to expose
\end{abstract}

\section{KARGER}

๑) 2016 S. Karger AG, Basel

E-Mail karger@karger.com

www.karger.com/ore cells and tissue cultures to elevated pressures. Herein, we discuss the methodology used to increase pressure, the main findings, and the relevance of in vitro models for the study of the pathophysiology of glaucoma.

C 2016 S. Karger AG, Basel

\section{Introduction}

Glaucoma is the second leading cause of irreversible blindness worldwide, and it is expected that 80 million people will suffer from this disease by the year 2020 [1]. The pathology shared by the heterogeneous group of glaucoma disorders is characterized by progressive optic nerve atrophy and retinal ganglion cell (RGC) death [2], which gradually lead to visual field loss. Advanced age and elevated intraocular pressure (IOP) are the main risk factors for the onset and progression of glaucoma. Nevertheless, patients presenting IOP values within the normal range may also develop the disease [3]. Since elevated IOP is the only modifiable risk factor, therapeutic strategies target lowering of the IOP and include pharmacological treatments, surgical procedures, and laser treatment. In some patients, the disease progresses despite effective control of the IOP [4], suggesting that alternative 
therapies should be used. Neuroprotection of RGC may have the potential to halt glaucomatous damage $[5,6]$. Although the research in the field of glaucoma is substantial, the pathological mechanisms involved in the onset and development of the disease are still not completely understood. Neuronal degeneration in glaucoma might be due to a combination of molecular factors, such as compromised retrograde axonal transport along the optic nerve, neurotrophin deprivation, increased oxidative stress, or excitotoxic stress caused by a glutamate impaired response $[7,8]$.

Several animal models have been developed to study glaucoma. Since elevated IOP is a main risk factor, relevant animal models for glaucoma would comprise RGC and optic nerve damage induced by ocular hypertension. Indeed, many of the animal models of glaucoma present an elevated IOP by reducing the outflow of aqueous humor (e.g. episcleral vein cauterization, episcleral vein ligation, laser photocoagulation of the limbar tissues, injection of hypertonic saline in the episcleral veins, and injection of microbeads in the anterior chamber) [for a revision of the animal models, see 9-11]. Many species have been used, including nonhuman primates which may better resemble the human anatomy and cellular response [12]. However, due to practical and economic reasons, rodents have been the most studied. Pressure-independent animal models have been used to model normal-tension glaucoma, and they have provided insights into the neurodegenerative mechanisms of RGC loss, like optic nerve crush, optic nerve transection, and retinal ischemia-reperfusion injury [13]. Animal models more closely resemble human glaucoma and have an unquestionable importance, but they are costly and time consuming and the results can be difficult to understand at the cellular level. Thus, in vitro models may help in the clarification of disease mechanisms and they may emerge as very useful tools to assess the response of individual cell populations against a noxious condition.

\section{Advantages of Using in vitro Models to Study Glaucoma}

The use of in vitro systems for the study of several pathologies has arisen as a great strategy to provide new insights into the molecular mechanisms of disease progression. In vitro models of elevated hydrostatic pressure (EHP) have been used in several contexts such as cancer $[14,15]$, hypertension and platelet aggregation [16], and cartilage and chondrocyte response [17]. Concerning the study of glaucoma, EHP has been used to mimic ocular hypertension. Several studies have reported the effect of EHP on cells of the trabecular meshwork [18-20] and Schlemm's canal [21] and other cell types [22]. The mechanisms whereby retinal cells sense mechanical pressure have not yet been completely elucidated, yet some possibilities have been considered [for a review, see 23]. Since neuroprotection has been claimed as a potential strategy to halt RGC loss in glaucoma, exposure of RGC to EHP has been used as a tool to obtain important preclinical data on the mechanisms of RGC loss and survival [2427].

The use of in vitro models for the study of glaucoma opened the possibility to study the cellular and molecular mechanisms that may contribute to the clarification of disease onset and progression. These models can be used in a wide variety of cell cultures, from cell lines to more complex models such as tissue cultures (retinal organotypic cultures) and ex vivo preparations (eye cup preparations). The opportunity to investigate whole tissue cultures poses clear advantages compared to a monolayer of cultured cells, allowing the study of cell-to-cell interactions and maintaining an anatomical structure under EHP [28]. Exposure of retinal tissue obtained from human postmortem donors to EHP may also prove to be a useful model for testing the effectiveness of neuroprotective strategies [29, 30]. Additionally, the use of EHP systems also promotes the reduction of animal use and the experimental variability intrinsic to animal models of glaucoma (table 1). Nevertheless, it is important to bear in mind that in vitro models do not mimic the intricacy of glaucomatous disease or replace animal models, but they do allow answering some important questions in a more rapid and less expensive way than animal models.

\section{The EHP Model}

Elevation of pressure constitutes the gold standard to model ocular hypertension in in vitro systems, and it has gained increasing attention in recent years. EHP should parallel the alterations observed in human glaucoma and animal models. Several systems have been developed to assess the responses of cells or tissue to elevated pressure using different time points and pressure magnitudes [31]. In the vast majority of glaucomatous patients, the values of IOP vary from 20 to $35 \mathrm{~mm} \mathrm{Hg}[8,32,33]$. To unravel the mechanisms that lead to RGC loss in glaucoma, in vitro models should recapitulate the effects of elevated pressure in relatively short time periods. In fact, most of the 
Table 1. Main advantages and disadvantages of using in vitro models in the context of glaucoma

\begin{tabular}{|c|c|}
\hline Advantages and disadvantages & Examples \\
\hline \multicolumn{2}{|l|}{ Advantages } \\
\hline Control of the environment & Stable control of the temperature and pressure influx inside the chamber \\
\hline Less time consuming & Periods ranging from $10 \mathrm{~min}$ to $120 \mathrm{~h}$ \\
\hline Small volumes & Better for high-throughput screening of multiple drugs \\
\hline Different experimental settings & Constant or fluctuating pressure, different time points and pressure intensities \\
\hline Reduction of animal numbers & Treatment is administered to cell lines or primary cultures, decreasing animal distress \\
\hline \multicolumn{2}{|l|}{ Disadvantages } \\
\hline Control vs. experimental groups & Control cultures are usually not in the same cell incubator as in experimental conditions \\
\hline Pressure levels do not reflect human glaucoma & Pressure ranging from 30 to $100 \mathrm{~mm} \mathrm{Hg}$ above the normal atmospheric pressure \\
\hline
\end{tabular}

reports mimicking chronic IOP elevation use pressures ranging from 30 to $100 \mathrm{~mm} \mathrm{Hg}$ above the atmospheric pressure during $10 \mathrm{~min}$ to $72 \mathrm{~h}$. All pressure values mentioned from this point on are above the atmospheric pressure (unless otherwise indicated) but, for clarity reasons, the term 'above atmospheric pressure' will be omitted.

Several systems designed to achieve an elevated pressure are based on pressurized chambers built in poly(methyl methacrylate) and connected to a source of air/ $\mathrm{CO}_{2}$ with a pressure regulator, and they are kept in a temperature-controlled environment. These systems provide a constant hydrostatic pressure within $\pm 1 \mathrm{~mm} \mathrm{Hg}$ and allow stable control of the pressure influx to the chamber [24-26, 33-37], while control cells are usually kept at atmospheric pressure $(760 \mathrm{~mm} \mathrm{Hg})$ in standard cell incubators $[22,25,33-35,37-42]$ or in some cases exposed to $15 \mathrm{~mm} \mathrm{Hg}$ to mimic normotensive conditions [27, 43-46]. Cell lines (RGC-5, B35, and PC12) [25-27, $35,39,40,47]$, primary cultures of RGC and astrocytes [41, 48-50], Müller cell cultures [38, 51, 52], or microglial cell cultures $[24,48,53,54]$, and more complex preparations like organotypic retinal cultures [24] and eye cup preparations $[44,45,55,56]$ have been exposed to EHP. In addition, human retinal cells, human organotypic retinal cultures [37], and human optic nerve head (ONH) astrocytes $[41,49,50]$ have been exposed to EHP.

\section{Chambers for Elevation of Pressure}

\section{Pressurized Chamber}

The most commonly used model of a pressurized chamber injects a mixture of humidified gas (95\% air/5\% $\mathrm{CO}_{2}$ ) through a pressure regulator into a poly(methyl methacrylate) box. This chamber is kept at $37^{\circ} \mathrm{C}$ in a standard incubator to allow temperature and humidity stabilization. The pressure inside the equipment is constantly monitored using a diaphragm-driven dial pressure gauge and it is kept stable within $\pm 1 \mathrm{~mm} \mathrm{Hg}$, from 0 to $200 \mathrm{~mm}$ $\mathrm{Hg}[25,26,33-36,39,40,57]$. Studies using this type of pressure chamber have demonstrated that exposure of neuronal cell lines (B35 and PC12) to $100 \mathrm{~mm} \mathrm{Hg}$ for $2 \mathrm{~h}$ triggers apoptosis, establishing a direct relationship between pressure and neuronal loss [35]. In addition, exposure of PC12 cells to 15 or $70 \mathrm{~mm} \mathrm{Hg}$ for $24 \mathrm{~h}$ and of RGC5 cells to $30 \mathrm{~mm} \mathrm{Hg}$ for $72 \mathrm{~h}$ also induces apoptosis, oxidative stress, mitochondrial changes, and a reduction in cellular ATP levels, supporting the role of mitochondrial oxidative injury in early glaucomatous damage $[26,39]$. Interestingly, exposure of organotypic retinal cultures to an increased pressure (50 or $90 \mathrm{~mm} \mathrm{Hg}$ ) does not promote alterations in RGC [58]. Nevertheless, exposure to a short pulse (1 min) at $30 \mathrm{~mm} \mathrm{Hg}$ severely damages RGC, accompanied by an increase in extracellular ATP and worsened by the exposure to repeated pulses [58]. In fact, relatively short exposures, i.e. $2 \mathrm{~h}$ at 60 or $100 \mathrm{~mm} \mathrm{Hg}$ and $6 \mathrm{~h}$ at $50 \mathrm{~mm} \mathrm{Hg}$, increase oxidative stress markers in RGC- 5 cells and induce cell apoptosis $[25,47]$ mediated by calpain activation via apoptosis-inducing factor [34]. These findings further support the role of oxidative stress as an initial event in glaucomatous neuronal damage $[25$, 47]. Exposure of RGC-5 cells to $30 \mathrm{~mm} \mathrm{Hg}$ for $72 \mathrm{~h}$ leads to mitochondrial fission, abnormal cristae depletion, alteration of the optic atrophy type 1 (OPA1) gene expression, and the release of OPA 1 and cytochrome C into the cytoplasm, triggering apoptotic cell death [40]. Furthermore, exposure of RGC-5 cells to 30 or $100 \mathrm{~mm}$ $\mathrm{Hg}$ for $2 \mathrm{~h}$ leads to a pressure-dependent increase in apop- 
tosis [25]. This graded response in cellular apoptosis is similar to the human condition when comparing acute glaucoma $(100 \mathrm{~mm} \mathrm{Hg})$ with chronic glaucoma (30 mm $\mathrm{Hg}$ ) [27]. Exposure of primary cultures of Müller cells and RGC to EHP (70 mm Hg for $48 \mathrm{~h}$ ) increases the secretion of pigment epithelium-derived factor and cell death, respectively [57]. Recently, other authors reported that exposure of a Müller cell line or organotypic retinal cell cultures obtained from mice and primates to different levels of pressure $(15,33$, and $46 \mathrm{~mm} \mathrm{Hg})$ for 24 or $72 \mathrm{~h}$ does not alter the expression of the complement genes but promotes an increase in the expression of glial fibrillary acidic protein (GFAP) [59], contrary to what was described in human glaucomatous samples [60]. These apparently contradictory results raise the question of whether in vitro models are suitable for the study of glaucoma, but they may also be explained by a lack of activated T cells [61] that may have a role in the human condition.

Studies using primary cultures of astrocytes obtained from human ONH have shown that their exposure to EHP ( $60 \mathrm{~mm} \mathrm{Hg}$ for 24, 48, or $72 \mathrm{~h}$ ) induces the expression of inducible nitric oxide synthase and alters the expression of several genes involved in important astrocytic functions $[49,62]$. Also, exposure of astrocytes to EHP (60 mm $\mathrm{Hg}$ for 30 or $90 \mathrm{~min}$ or for 3,6 , or $24 \mathrm{~h}$ ) changes the distribution of connexin 43 , altering the intercellular communication mediated by gap junctions, which may impact the homeostasis of nonmyelinated axons of RGC in the $\mathrm{ONH}$ [63]. Exposure of rat retinal astrocyte cultures to EHP $(70 \mathrm{~mm} \mathrm{Hg}$ for $24 \mathrm{~h}$ ) decreases extracellular interleukin (IL)-6 levels [48]. In contrast, EHP induces an influx of extracellular $\mathrm{Ca}^{2+}$, activation of the ubiquitin proteasome pathway and NFKB, leading to an increased expression of IL-6 in microglia [48]. This increase in IL-6 expression seems to be partially dependent on the activation of transient receptor potential vanilloid-1 receptor (TRPV1) and other ruthenium red-sensitive channels [53]. Exposure of RGC cultures to EHP ( $70 \mathrm{~mm} \mathrm{Hg}$ for $24 \mathrm{~h}$ ) increases the influx of extracellular $\mathrm{Ca}^{2+}$ and TRPV1 activation, which induces apoptosis [64]. Further studies have demonstrated that the release of IL- 6 by microglial cells elicited by EHP is able to reduce the pressure-induced apoptotic cascade triggered by glial cells [33]. A recent study reported microglia activation and upregulation of adenosine $A_{2 A}$ receptors in retinal microglial cell cultures following exposure to $70 \mathrm{~mm} \mathrm{Hg}$ for 4 or $24 \mathrm{~h}$ [54]. Microglia activation and RGC death were also reported in retinal organotypic cultures exposed to the same conditions [24]. Using this model, the authors unraveled a possible mechanosensitive role for retinal microglia which become reactive and promote the inflammatory response following an EHP challenge. Interestingly, neutralization of the actions of the proinflammatory cytokines tumor necrosis factor (TNF) and IL- $1 \beta$ prevents RGC death, pointing to neuroinflammation as a key mediator of the neurodegenerative process triggered by EHP [24].

\section{Hydraulic Pressurizing Chamber}

A hydraulic pressurizing chamber is composed of 2 chambers, a gas filling system, a hydraulic pump, and a hydraulic cylinder. The pressure cylinder is made of steel, while the nonpressurized chamber is made in poly(vinyl chloride) plastic. The pressure inside the chamber is obtained using a hydraulic system where the oil flow generated by the hydraulic pump is conducted to the hydraulic cylinder underneath the pressure chamber. Elevated pressure is obtained via compression of the gas phase inside the chamber. The pressure is regulated by a pressure valve, which transfers the necessary force to the chamber filled with $95 \%$ air $/ 5 \% \mathrm{CO}_{2}$ via a computer-controlled system. This system is kept at $37^{\circ} \mathrm{C}$ in a standard incubator and the pressure is constantly monitored. In this case, the control cultures are kept in the reference nonpressurized chamber [18, 22, 41, 42, 49, 50, 65, 66].

Exposure of rat retinal cells (E1A.NR3 cell line) to 50 $\mathrm{mm} \mathrm{Hg}$ for $6 \mathrm{~h}$ altered the cell morphology, increased the basal adenylyl cyclase activity, and decreased the forskolin-evoked adenylyl cyclase activity without compromising cell viability [22]. This device has also been used to challenge human $\mathrm{ONH}$ astrocytes at $60 \mathrm{~mm} \mathrm{Hg}$ for 6 or $48 \mathrm{~h}$, inducing cell migration [67] and causing alterations in cell morphology and the distribution of GFAP, increasing the levels of neural cell adhesion molecule and small heat shock protein $27[41,50]$. These proteins are involved in cytoskeleton alterations and cellular migration of reactive astrocytes, and they are increased in astrocytes of the $\mathrm{ONH}$ of patients with glaucoma $[41,50]$. In addition, exposure of a cell line of human astrocytes to $60 \mathrm{~mm} \mathrm{Hg}$ for $6 \mathrm{~h}$ altered the cell morphology and promoted the redistribution of actin stress fibers [22].

Exposure of individual cultures or cocultures of glial cells and RGC to $50 \mathrm{~mm} \mathrm{Hg}$ for $72 \mathrm{~h}$ promoted the release of NO and TNF by glial cells and RGC apoptosis [42]. The presence of a selective inducible nitric oxide synthase inhibitor or an anti-TNF antibody decreased RGC apoptosis. The role of inflammatory mediators released by glial cells on RGC loss induced by EHP was further demonstrated by the observation that exposure of RGC cultures to conditioned media of glial cells exposed to EHP triggers RGC apoptosis [42]. In addition, the expression of
80

Ophthalmic Res 2017;57:77-86

DOI: $10.1159 / 000448480$
Aires/Ambrósio/Santiago 
several genes affecting multiple metabolic and signaling pathways was altered in a rat Müller cell line exposed to EHP for $6 \mathrm{~h}$ [68].

In vitro experiments may also provide important data on the impact of elevated pressure in cells obtained from human populations with different susceptibilities to glaucoma. The prevalence of glaucoma is higher in Black Americans of African American ancestry than in Caucasian American populations of European ancestry [69]. Exposure of $\mathrm{ONH}$ astrocytes from Caucasian and African American donors to $60 \mathrm{~mm} \mathrm{Hg}$ for 24 to $96 \mathrm{~h}$ increases the expression of the myosin light chain kinase isoforms MYLK-130 and MYLK-210 [70]. However, transforming growth factor- $\beta_{2}\left(\mathrm{TGF} \beta_{2}\right)$ was found to be upregulated only in $\mathrm{ONH}$ astrocytes of Caucasian donors [70]. TGF $\beta_{2}$ is increased in glaucomatous $\mathrm{ONH}$ and colocalizes with astrocytes [71]. Thus, TGF $\beta_{2}$ upregulation triggered by $\mathrm{EHP}$ in $\mathrm{ONH}$ astrocytes of Caucasian donors suggests that it may be an important indicator of reactive astrocytes in vitro and glaucomatous alterations in the $\mathrm{ONH}$. Moreover, $\mathrm{ONH}$ astrocytes from African American donors are more sensitive to EHP than $\mathrm{ONH}$ astrocytes from Caucasian donors with respect to $3^{\prime}, 5^{\prime}$-cyclic adenosine monophosphate-mediated signaling, while $\mathrm{ONH}$ astrocytes from Caucasian donors are more sensitive to extracellular ATP-mediated signaling [29]. This group of results demonstrates that different susceptibilities to the development of glaucoma may be further studied in vitro, allowing the identification of potential molecular targets for different human populations. Taken together, all of these results demonstrate that EHP triggers astrocyte reactivity, paralleling the observations in glaucomatous eyes $[41,72]$.

\section{Pressurized Live-Cell Imaging Chamber}

Live-cell imaging under exposure to elevated pressure has also been described [43]. The pressurized live-cell imaging chamber has been installed on the stage of an Olympus IX71 inverted optical microscope. In order to increase the pressure inside the chamber to $100 \mathrm{~mm} \mathrm{Hg}$, a mixture of prehumidified and heated $95 \%$ air $/ 5 \% \mathrm{CO}_{2}$ is injected through a pressure regulator at $37^{\circ} \mathrm{C}$ under continuous perfusion [43]. Exposure of RGC-5 cells to EHP $(100 \mathrm{~mm} \mathrm{Hg}$ for $20 \mathrm{~h}$ ) induces apoptosis and morphological changes mediated by early alterations in $\mathrm{Ca}^{2+} \mathrm{dy}-$ namics and caspase-3/7 activation [43]. Unfortunately, one major disadvantage of this experimental setup is that the control and experimental procedures are not performed at the same time, which may lead to an increased variability in cell response.

\section{Pressure Variation Chamber}

There is mounting evidence that IOP fluctuations play an important role in the development and progression of glaucoma $[73,74]$. Therefore, exposing cells to fluctuating pressures may provide a better correlation between the in vitro situation and the clinical presentation of glaucoma [75].

A pressurized chamber was designed to mimic IOP oscillations by performing cycles of 10 and $100 \mathrm{~mm} \mathrm{Hg}$ each minute for $1 \mathrm{~h}$. The chamber is connected to a mass flow controller which injects a mixture of $95 \%$ air $/ 5 \%$ $\mathrm{CO}_{2}$ that simultaneously regulates the internal pressure and the gas flow. The system is connected to a computer with appropriate software for internal pressure regulation over time [37]. Exposure of primary rat RGC cultures to either fluctuating pressures from 0 to 30 or $60 \mathrm{~mm} \mathrm{Hg}$ or a constant pressure of 30 or $90 \mathrm{~mm} \mathrm{Hg}$ for $72 \mathrm{~h}$ does not elicit cell apoptosis but does increase the susceptibility of RGC to glutamate excitoxicity, which has been considered to play an important role in glaucomatous degeneration [76]. Using a similar approach, exposure of human organotypic retinal cultures to fluctuating pressures (10-100 mm Hg; 1 cycle/min) for 24 or $48 \mathrm{~h}$ neither triggered RGC death nor altered cell survival pathways or the retinal structure [37]. It remains to be determined whether other pressure oscillations result in different outcomes for RGC. One major point that must be taken into consideration is that pressure oscillations in the human eye are dependent on the circadian cycle, which is difficult to model in vitro $[4,77,78]$.

\section{Pressurized Cell Culture Flasks}

Cell culture tissue flasks can also be used to challenge cells with elevated pressure. In this setup, T75 culture flasks are adapted with a pressure gauge and a syringe to pump the air mixture of $95 \%$ air $/ 5 \% \mathrm{CO}_{2}$, while control culture flasks are maintained in a standard cell incubator $[38,51,52]$. Using this system, exposure of primary Müller cell cultures to $40 \mathrm{~mm} \mathrm{Hg}$ for $24 \mathrm{~h}$ increased the expression of inwardly rectifying potassium channels, glutamate aspartate transporter, and glutamine synthetase, indicating that Müller cells are susceptible to EHP $[38,51$, 52]. This simple model was able to yield different values of pressure for $24 \mathrm{~h}$. However, incubation of cells with drugs or replacement of the culture medium requires the system to be disconnected from the air source, introducing handling bias. 


\section{Liquid-Column Pressure Model}

EHP can also be achieved via immersion of cells in custom-made columns filled with culture medium [79]. Control conditions are attained by using the same volume of culture medium but in horizontal columns. Both control and experimental setups are placed in a humidified incubator at $37^{\circ} \mathrm{C}$ with $5 \% \mathrm{CO}_{2}$. Exposure of type $1 \mathrm{~B}$ astrocytes to $15 \mathrm{~mm} \mathrm{Hg}$ for 1-5 days promotes cell proliferation and migration, as well as synthesis and secretion of soluble elastin, which may be correlated with the formation of elastin fibers involved in tissue remodeling described in glaucoma $[79,80]$. Exposure of rat optic nerve astrocytes to $15 \mathrm{~mm} \mathrm{Hg}$ for $15 \mathrm{~min}$ promotes the release of calcium from a ryanodine-sensitive cytoplasmic store, leading to extracellular-signal-regulated kinases activation and an astrocytic response [81]. In this model, EHP is achieved by increasing the height of the culture medium column. This system may pose some difficulties, such as the fact that each pressure level needs its own column to set the proper height of culture medium and the increased volume of culture medium necessary to sustain EHP hinders the application pharmacological treatments. Also, the secreted molecules may have different impacts on the cells depending on their concentration in the cell culture medium supernatant, introducing a confounding variable.

\section{Centrifugal Force Loading Model}

Another model with the purpose of reproducing a state that closely mimics the pressurized state was developed by applying centrifugal force. The device comprises a rotating vessel installed within an incubator, a power supply unit, a control unit, and a cooling motor. The rotor spins at 1-30 rotations per minute and the cells experience a centrifugal force equivalent to 16,28 , or $48 \mathrm{~mm} \mathrm{Hg}$ [82]. Control cultures are kept at atmospheric pressure in a standard incubator. Exposure of isolated rat RGC to a centrifugal force equivalent to 16 or $28 \mathrm{~mm} \mathrm{Hg}$ for $48 \mathrm{~h}$ decreased RGC survival, and when these cells were exposed to a centrifugal force equivalent to $33 \mathrm{~mm} \mathrm{Hg}$ for $72 \mathrm{~h}$ the number of neurites decreased. Nevertheless, exposure of primary retinal glial cell cultures to a centrifugal force equivalent to 16,28 , or $48 \mathrm{~mm} \mathrm{Hg}$ for $48 \mathrm{~h}$ did not alter cell survival. Interestingly, the exposure of cocultures of RGC and glial cells promotes viability of RGC, indicating that retinal glial cells exhibit protective effects on RGC subjected to centrifugal force loading [82].

\section{Ex vivo Pressure Models}

\section{Pressure Chamber for Bovine Eye Cup Preparations}

In addition to cell and tissue cultures, ex vivo models have been developed in order to better understand the pathophysiology of ocular hypertension.

Bovine eye cup preparations were loaded with air or nitrogen to increase the pressure. The pressure chamber consists of a $60-\mathrm{ml}$ plastic jar with a screw cap to which a 3 -way valve is attached. The pressure inside the chamber is constantly monitored using a digital pressure transducer [56]. The authors found that exposure of bovine eye cup preparations to EHP increases extracellular ATP levels [56]. These findings are correlated with increased ATP levels found in the anterior chamber of glaucomatous patients $[55,83]$ and suggest a link between pressure and RGC loss in glaucoma. This model was able to sustain the pressure for only $1 \mathrm{~h}$, a relative short period to assess some cellular responses. In addition, taking into consideration that each eye cup preparation is subjected to EHP in an independent chamber, there is a potential risk of increasing experiment variability.

\section{Pressure Chamber for Rat Eye Cup Preparations:}

Liquid-Column Pressure Model

Eye cup preparations from rats were submitted to EHP via submersion in a glass cylinder with artificial cerebrospinal fluid (aCSF). The pressure at the bottom of the device is calculated as $\mathrm{P}=\rho \mathrm{gH}$, where $\mathrm{P}=$ pressure, $\rho=$ density of the aCSF, $\mathrm{g}=$ gravity, and $\mathrm{H}=$ height of the aCSF column. Control cultures are kept at a depth of $13.5 \mathrm{~cm}$ to attain a pressure of $10 \mathrm{~mm} \mathrm{Hg}$. The culture medium is constantly bubbled with $95 \%$ air/5\% $\mathrm{CO}_{2}$ to ensure proper oxygenation of the tissue [44-46]. Using this model, exposure of rat ex vivo retinal preparations to $75 \mathrm{~mm} \mathrm{Hg}$ for $24 \mathrm{~h}$ caused axonal swelling in the nerve fiber layer mediated by the activation of ionotropic glutamate receptors [44]. In addition, EHP downregulates glutamate aspartate transporter expression and inhibits glutamine synthetase activity, suggesting disruption of glutamate metabolism in glial cells [45]. Furthermore, EHP increases the synthesis of allopregnanolone, an endogenous inhibitory pregnane neurosteroid, in the retina, mainly via the N-methyl-D-aspartate receptor. Administration of allopregnanolone diminishes pressure-induced retinal degeneration via activation of $\gamma$-aminobutyric acid type A (GABA-A) receptors [46]. This model is similar to the liquid-column pressure model using a monolayer of cells, meaning that comparable disadvantages may be indicated.
Aires/Ambrósio/Santiago 


\section{Stretch-Based Models}

In a glaucomatous eye, elevated IOP induces compression, stretching, and rearrangement of the cribriform plates in the $\mathrm{ONH}$, resulting in cupping of the optic disc [84]. In fact, cells in the lamina cribrosa in the ONH are continuously exposed to mechanical strain. In addition to the models based on the increase in pressure, models inducing mechanical stretch have been also developed to study alterations occurring in glaucoma. These models use commercially available straining systems allowing a sustained increase in strain or variable pulses [85, 86], whereas control cells are kept in static conditions. Exposure of primary cultures of human lamina cribrosa cells to a mechanical strain of $15 \%$ stretch at $1 \mathrm{~Hz}$ for $24 \mathrm{~h}$ changes the expression of genes related to cell proliferation, growth factor activity, and signal transduction [85]. Furthermore, stretch changes the expression of genes that regulate the extracellular matrix in these cells, which is prevented by the blockade of calcium channels, highlighting the role of calcium influx in matrix remodeling in glaucoma [87]. In addition, exposure of human lamina cribrosa cells to an elongation of $3 \%$ at $1 \mathrm{~Hz}$ and then to 12.5 or $20 \%$ stretch alters the expression of several genes involved in extracellular matrix dynamics [86]. These studies indicate that stretch-based approaches may also be relevant to the study of alterations in glaucoma, i.e. to better understand cell-to-cell communication and structural alterations.

\section{Important Considerations when Using EHP Systems}

When studying the effects of EHP, there are several conditions and confounding factors that need to be carefully examined beforehand. As described above, most of the pressurized systems are custom-made, thus presenting variability in experimental settings in different laboratories even when the same model is used. Definitely, it is of utmost importance to validate the device in use and consider all potential confounding factors such as $\mathrm{pH}$, temperature, osmolarity, oxygenation, and alterations in gas composition [discussed in $37,48,88$ ]. In addition, it should be emphasized that EHP only constitutes a small component of the forces associated with elevated IOP. In the eye, pressure acts in a closed system and there is a differential pressure between the inside and the outside of the eye, similarly to a closed vessel. Within a closed vessel, pressure has two mechanical effects: it directly causes stress transversely through a section of the vessel wall along a radial axis, and it creates an in-plane tensile stress in the vessel wall, which acts along the surface of a vessel wall in a circumferential direction [as discussed in 89]. This latter stress is not modeled in an experimental system where cultured cells or tissue are placed within a chamber where the EHP is raised.

\section{Conclusions}

Elevated IOP is a major risk factor for the onset and development of glaucoma, a disease characterized by loss of RGC and damage to the optic nerve. Several systems have been developed to expose cells or tissues to elevated pressures, mimicking ocular hypertension. Therefore, pressurized chambers have become an important tool to study the pathophysiology of glaucoma, providing insight into the impact of elevated pressure on individual cell types. Another advantage of the exposure of cells to EHP is that, prior to assessment in animal models, it allows a better and rational selection of putative neuroprotective agents.

In vitro models will never substitute animal studies, but they are important tools in preclinical studies in the field of glaucoma. Though much less complex than animal models, in vitro models of EHP offer the advantage of having controlled experimental conditions, clarifying individual cell responses to stress and allowing preliminary targeting of a specific cell type or pathway involved in the progression of glaucoma. There is no doubt that more studies are needed in this important research field, which will allow the development of new relevant models to study RGC neurodegeneration and neuroprotection in the context of glaucoma.

\section{Acknowledgement}

The work was supported by FCT(PTDC/BIM-MEC/0913/2012, PEst-C/SAU/UI3282/2011-2013 and UID/NEU/04539/2013), COMPETE-FEDER (FCOMP-01-0124-FEDER-028417 and POCI-01-0145-FEDER-007440), CNC.IBILI, and AIBILI (Portugal).

\section{Disclosure Statement}

The authors declare no competing or financial interests. 


\section{References}

1 Quigley HA, Broman AT: The number of people with glaucoma worldwide in 2010 and 2020. Br J Ophthalmol 2006;90:262-267.

2 Vohra R, Tsai JC, Kolko M: The role of inflammation in the pathogenesis of glaucoma. Surv Ophthalmol 2013;58:311-320.

3 Fan N, Wang P, Tang L, Liu X: Ocular blood flow and normal tension glaucoma. Biomed Res Int 2015;2015:308505.

4 Cohen LP, Pasquale LR: Clinical characteristics and current treatment of glaucoma. Cold Spring Harb Perspect Med DOI: 10.1101/ cshperspect.a017236.

5 Chang EE, Goldberg JL: Glaucoma 2.0: neuroprotection, neuroregeneration, neuroenhancement. Ophthalmology 2012;119:979986.

6 Cordeiro MF, Levin LA: Clinical evidence for neuroprotection in glaucoma. Am J Ophthalmol 2011;152:715-716.

7 Madeira MH, Boia R, Santos PF, Ambrósio AF, Santiago AR: Contribution of microgliamediated neuroinflammation to retinal degenerative diseases. Mediators Inflamm 2015; 2015:15.

8 Almasieh M, Wilson AM, Morquette B, Cueva Vargas JL, Di Polo A: The molecular basis of retinal ganglion cell death in glaucoma. Prog Retin Eye Res 2012;31:152-181.

9 Ishikawa M, Yoshitomi T, Zorumski CF, Izumi Y: Experimentally induced mammalian models of glaucoma. Biomed Res Int 2015; 2015:281214.

10 Morrison JC, Cepurna Ying Guo WO, Johnson EC: Pathophysiology of human glaucomatous optic nerve damage: insights from rodent models of glaucoma. Exp Eye Res 2011; 93:156-164.

11 Fernandes KA, Harder JM, Williams PA, Rausch RL, Kiernan AE, Nair KS, Anderson MG, John SW, Howell GR, Libby RT: Using genetic mouse models to gain insight into glaucoma: past results and future possibilities. Exp Eye Res 2015;141:42-56.

12 Burgoyne CF: The non-human primate experimental glaucoma model. Exp Eye Res 2015;141:57-73.

13 Goldblum D, Mittag T: Prospects for relevant glaucoma models with retinal ganglion cell damage in the rodent eye. Vision Res 2002;42: 471-478.

14 Tokuda S, Kim YH, Matsumoto H, Muro S, Hirai T, Mishima M, Furuse M: Effects of hydrostatic pressure on carcinogenic properties of epithelia. PLoS One 2015;10:e0145522.

15 Kao YC, Lee CH, Kuo PL: Increased hydrostatic pressure enhances motility of lung cancer cells. Conf Proc IEEE Eng Med Biol Soc 2014;2014:2928-2931.

16 Rao F, Yang RQ, Chen XS, Xu JS, Fu HM, Su $\mathrm{H}$, Wang L: PPARgamma ligands decrease hydrostatic pressure-induced platelet aggregation and proinflammatory activity. PLoS One 2014;9:e89654
17 Kaarniranta K, Elo M, Sironen R, Lammi MJ, Goldring MB, Eriksson JE, Sistonen L, Helminen HJ: Hsp70 accumulation in chondrocytic cells exposed to high continuous hydrostatic pressure coincides with mRNA stabilization rather than transcriptional activation. Proc Natl Acad Sci USA 1998;95: 2319-2324.

18 Yang JL, Neufeld AH, Zorn MB, Hernandez MR: Collagen type I mRNA levels in cultured human lamina cribrosa cells: effects of elevated hydrostatic pressure. Exp Eye Res 1993;56: 567-574.

19 Lei Y, Stamer WD, Wu J, Sun X: Cell senescence reduced the mechanotransduction sensitivity of porcine angular aqueous plexus cells to elevation of pressure. Invest Ophthalmol Vis Sci 2014;55:2324-2328.

20 Obazawa M, Mashima Y, Sanuki N, Noda S, Kudoh J, Shimizu N, Oguchi Y, Tanaka Y, Iwata T: Analysis of porcine optineurin and myocilin expression in trabecular meshwork cells and astrocytes from optic nerve head. Invest Ophthalmol Vis Sci 2004;45:2652-2659.

21 Burke AG, Zhou W, O'Brien ET, Roberts BC, Stamer WD: Effect of hydrostatic pressure gradients and Na2EDTA on permeability of human Schlemm's canal cell monolayers. Curr Eye Res 2004;28:391-398.

22 Wax MB, Tezel G, Kobayashi S, Hernandez MR: Responses of different cell lines from ocular tissues to elevated hydrostatic pressure. Br J Ophthalmol 2000;84:423-428.

23 Krizaj D, Ryskamp DA, Tian N, Tezel G, Mitchell CH, Slepak VZ, Shestopalov VI: From mechanosensitivity to inflammatory responses: new players in the pathology of glaucoma. Curr Eye Res 2014;39:105-119.

24 Madeira MH, Elvas F, Boia R, Goncalves FQ, Cunha RA, Ambrosio AF, Santiago AR: Adenosine A2AR blockade prevents neuroinflammation-induced death of retinal ganglion cells caused by elevated pressure. J Neuroinflammation 2015;12:115.

25 Liu Q, Ju WK, Crowston JG, Xie F, Perry G, Smith MA, Lindsey JD, Weinreb RN: Oxidative stress is an early event in hydrostatic pressure induced retinal ganglion cell damage. Invest Ophthalmol Vis Sci 2007;48:4580-4589.

26 Ju WK, Liu Q, Kim KY, Crowston JG, Lindsey JD, Agarwal N, Ellisman MH, Perkins GA, Weinreb RN: Elevated hydrostatic pressure triggers mitochondrial fission and decreases cellular ATP in differentiated RGC-5 cells. Invest Ophthalmol Vis Sci 2007;48:2145-2151.

27 Agar A, Li S, Agarwal N, Coroneo MT, Hill MA: Retinal ganglion cell line apoptosis induced by hydrostatic pressure. Brain Res 2006;1086:191-200.

28 Johnson TV, Martin KR: Development and characterization of an adult retinal explant organotypic tissue culture system as an in vitro intraocular stem cell transplantation model. Invest Ophthalmol Vis Sci 2008;49:35033512.
29 Chen L, Lukas TJ, Hernandez MR: Hydrostatic pressure-dependent changes in cyclic AMP signaling in optic nerve head astrocytes from Caucasian and African American donors. Mol Vis 2009;15:1664-1672.

30 Osborne A, Hopes M, Wright P, Broadway DC, Sanderson J: Human organotypic retinal cultures (HORCs) as a chronic experimental model for investigation of retinal ganglion cell degeneration. Exp Eye Res 2016;143:2838.

31 Brown TD: Techniques for mechanical stimulation of cells in vitro: a review. J Biomech 2000;33:3-14.

32 Mantravadi AV, Vadhar N: Glaucoma. Prim Care 2015;42:437-449.

33 Sappington RM, Chan M, Calkins DJ: Interleukin-6 protects retinal ganglion cells from pressure-induced death. Invest Ophthalmol Vis Sci 2006; 47:2932-2942.

34 Shang L, Huang JF, Ding W, Chen S, Xue LX, Ma RF, Xiong K: Calpain: a molecule to induce AIF-mediated necroptosis in RGC-5 following elevated hydrostatic pressure. BMC Neurosci 2014; 15:63.

35 Agar A, Yip SS, Hill MA, Coroneo MT: Pressure related apoptosis in neuronal cell lines. J Neurosci Res 2000;60:495-503.

36 Sumpio BE, Widmann MD, Ricotta J, Awolesi MA, Watase M: Increased ambient pressure stimulates proliferation and morphologic changes in cultured endothelial cells. J Cell Physiol 1994;158:133-139.

37 Osborne A, Aldarwesh A, Rhodes JD, Broadway DC, Everitt C, Sanderson J: Hydrostatic pressure does not cause detectable changes in survival of human retinal ganglion cells. PLoS One 2015;10:e0115591.

38 Yu J, Zhong Y, Cheng Y, Shen X, Wang J, Wei Y: Effect of high hydrostatic pressure on the expression of glutamine synthetase in rat retinal Müller cells cultured in vitro. Exp Ther Med 2011;2:513-516.

39 Tok L, Naziroglu M, Uguz AC, Tok O: Elevated hydrostatic pressures induce apoptosis and oxidative stress through mitochondrial membrane depolarization in PC12 neuronal cells: a cell culture model of glaucoma. J Recept Signal Transduct Res 2014;34:410-416.

$40 \mathrm{Ju}$ WK, Kim KY, Lindsey JD, Angert M, Patel A, Scott RT, Liu Q, Crowston JG, Ellisman $\mathrm{MH}$, Perkins GA, Weinreb RN: Elevated hydrostatic pressure triggers release of OPA1 and cytochrome $\mathrm{C}$, and induces apoptotic cell death in differentiated RGC- 5 cells. Mol Vis 2009;15:120-134.

41 Salvador-Silva M, Ricard CS, Agapova OA, Yang P, Hernandez MR: Expression of small heat shock proteins and intermediate filaments in the human optic nerve head astrocytes exposed to elevated hydrostatic pressure in vitro. J Neurosci Res 2001;66:59-73. 
42 Tezel G, Wax MB: Increased production of tumor necrosis factor-alpha by glial cells exposed to simulated ischemia or elevated hydrostatic pressure induces apoptosis in cocultured retinal ganglion cells. J Neurosci 2000; 20:8693-8700.

43 Lee JK, Lu S, Madhukar A: Real-time dynamics of $\mathrm{Ca}^{2+}$, caspase-3/7, and morphological changes in retinal ganglion cell apoptosis under elevated pressure. PLoS One 2010;5: e13437.

44 Ishikawa M, Yoshitomi T, Zorumski CF, Izumi Y: Effects of acutely elevated hydrostatic pressure in a rat ex vivo retinal preparation. Invest Ophthalmol Vis Sci 2010;51:64146423.

45 Ishikawa $\mathrm{M}$, Yoshitomi T, Zorumski CF, Izumi Y: Downregulation of glutamine synthetase via GLAST suppression induces retinal axonal swelling in a rat ex vivo hydrostatic pressure model. Invest Ophthalmol Vis Sci 2011;52:6604-6616.

46 Ishikawa M, Yoshitomi T, Zorumski CF, Izumi Y: Neurosteroids are endogenous neuroprotectants in an ex vivo glaucoma model. Invest Ophthalmol Vis Sci 2014;55:8531-8541.

47 Liu B, Ma X, Guo D, Guo Y, Chen N, Bi H: Neuroprotective effect of alpha-lipoic acid on hydrostatic pressure-induced damage of retinal ganglion cells in vitro. Neurosci Lett 2012; 526:24-28.

48 Sappington RM, Calkins DJ: Pressure-induced regulation of IL-6 in retinal glial cells: involvement of the ubiquitin/proteasome pathway and NFkappaB. Invest Ophthalmol Vis Sci 2006;47:3860-3869.

49 Liu B, Neufeld AH: Nitric oxide synthase- 2 in human optic nerve head astrocytes induced by elevated pressure in vitro. Arch Ophthalmol 2001;119:240-245.

50 Ricard CS, Kobayashi S, Pena JD, SalvadorSilva M, Agapova O, Hernandez MR: Selective expression of neural cell adhesion molecule (NCAM)-180 in optic nerve head astrocytes exposed to elevated hydrostatic pressure in vitro. Brain Res Mol Brain Res 2000;81: 62-79.

$51 \mathrm{Yu}$ J, Chen C, Wang J, Cheng Y, Wu Q, Zhong $Y$, Shen X: In vitro effect of adenosine on the mRNA expression of Kir 2.1 and Kir 4.1 channels in rat retinal Müller cells at elevated hydrostatic pressure. Exp Ther Med 2012;3: 617-620.

52 Yu J, Zhong Y, Shen X, Cheng Y, Qi J, Wang $\mathrm{J}$ : In vitro effect of adenosine $\mathrm{A} 2 \mathrm{~A}$ receptor antagonist SCH 442416 on the expression of glutamine synthetase and glutamate aspartate transporter in rat retinal Müller cells at elevated hydrostatic pressure. Oncol Rep 2012;27: 748-752.

53 Sappington RM, Calkins DJ: Contribution of TRPV1 to microglia-derived IL- 6 and NFkap$\mathrm{paB}$ translocation with elevated hydrostatic pressure. Invest Ophthalmol Vis Sci 2008;49: 3004-3017.
54 Madeira MH, Boia R, Elvas F, Martins T, Cunha RA, Ambrosio AF, Santiago AR: Selective $\mathrm{A} 2 \mathrm{~A}$ receptor antagonist prevents microglia-mediated neuroinflammation and protects retinal ganglion cells from high intraocular pressure-induced transient ischemic injury. Transl Res 2016169:112-128.

55 Zhang X, Li A, Ge J, Reigada D, Laties AM, Mitchell $\mathrm{CH}$ : Acute increase of intraocular pressure releases ATP into the anterior chamber. Exp Eye Res 2007;85:637-643.

56 Reigada D, Lu W, Zhang M, Mitchell CH: Elevated pressure triggers a physiological release of ATP from the retina: possible role for pannexin hemichannels. Neuroscience 2008; 157:396-404

57 Lee SJ, Duncan DS, Echevarria FD, McLaughlin WM, Hatcher JB, Sappington RM: Pressure-induced alterations in PEDF and PEDF$\mathrm{R}$ expression: implications for neuroprotective signaling in glaucoma. J Clin Exp Ophthalmol 2015;6.

58 Resta V, Novelli E, Vozzi G, Scarpa C, Caleo M, Ahluwalia A, Solini A, Santini E, Parisi V, Di Virgilio F, Galli-Resta L: Acute retinal ganglion cell injury caused by intraocular pressure spikes is mediated by endogenous extracellular ATP. Eur J Neurosci 2007;25:27412754.

59 Astafurov K, Dong CQ, Panagis L, Kamthan G, Ren L, Rozenboym A, Perera TD, Coplan JD, Danias J: Complement expression in the retina is not influenced by short-term pressure elevation. Mol Vis 2014;20:140-152.

60 Tezel G, Yang X, Luo C, Kain AD, Powell DW, Kuehn MH, Kaplan HJ: Oxidative stress and the regulation of complement activation in human glaucoma. Invest Ophthalmol Vis Sci 2010;51:5071-5082.

61 Juel HB, Kaestel C, Folkersen L, Faber C, Heegaard NH, Borup R, Nissen MH: Retinal pigment epithelial cells upregulate expression of complement factors after co-culture with activated T cells. Exp Eye Res 2011;92:180188.

62 Yang P, Agapova O, Parker A, Shannon W, Pecen P, Duncan J, Salvador-Silva M, Hernandez MR: DNA microarray analysis of gene expression in human optic nerve head astrocytes in response to hydrostatic pressure. Physiol Genomics 2004;17:157-169.

63 Malone P, Miao H, Parker A, Juarez S, Hernandez MR: Pressure induces loss of gap junction communication and redistribution of connexin 43 in astrocytes. Glia 2007;55:10851098.

64 Sappington RM, Sidorova T, Long DJ, Calkins DJ: TRPV1: contribution to retinal ganglion cell apoptosis and increased intracellular $\mathrm{Ca}^{2+}$ with exposure to hydrostatic pressure. Invest Ophthalmol Vis Sci 2009;50:717-728.

65 Parkkinen JJ, Ikonen J, Lammi MJ, Laakkonen J, Tammi M, Helminen HJ: Effects of cyclic hydrostatic pressure on proteoglycan synthesis in cultured chondrocytes and articular cartilage explants. Arch Biochem Biophys 1993;300:458-465.
66 Oishi Y, Uezono Y, Yanagihara N, Izumi F, Nakamura T, Suzuki K: Transmural compression-induced proliferation and DNA synthesis through activation of a tyrosine kinase pathway in rat astrocytoma RCR-1 cells. Brain Res 1998;781:159-166.

67 Tezel G, Hernandez MR, Wax MB: In vitro evaluation of reactive astrocyte migration, a component of tissue remodeling in glaucomatous optic nerve head. Glia 2001;34:178189

68 Xue W, Du P, Lin S, Dudley VJ, Hernandez MR, Sarthy VP: Gene expression changes in retinal Müller (glial) cells exposed to elevated pressure. Curr Eye Res 2011;36:754-767.

69 Tham YC, LiX, Wong TY, Quigley HA, Aung T, Cheng CY: Global prevalence of glaucoma and projections of glaucoma burden through 2040: a systematic review and meta-analysis. Ophthalmology 2014;121:2081-2090.

70 Miao H, Crabb AW, Hernandez MR, Lukas TJ: Modulation of factors affecting optic nerve head astrocyte migration. Invest Ophthalmol Vis Sci 2010;51:4096-4103.

71 Pena JD, Taylor AW, Ricard CS, Vidal I, Hernandez MR: Transforming growth factor beta isoforms in human optic nerve heads. Br J Ophthalmol 1999;83:209-218.

72 Schneider M, Fuchshofer R: The role of astrocytes in optic nerve head fibrosis in glaucoma. Exp Eye Res 2016;142:49-55.

73 Caprioli J, Varma R: Intraocular pressure: modulation as treatment for glaucoma. Am J Ophthalmol 2011;152:340-344 e342.

74 Asrani S, Zeimer R, Wilensky J, Gieser D, Vitale S, Lindenmuth K: Large diurnal fluctuations in intraocular pressure are an independent risk factor in patients with glaucoma. J Glaucoma 2000;9:134-142.

75 Aptel F, Lesoin A, Chiquet C, Aryal-Charles N, Noel C, Romanet JP: Long-term reproducibility of diurnal intraocular pressure patterns in patients with glaucoma. Ophthalmology 2014;121:1998-2003.

76 Aihara M, Chen YN, Uchida S, Nakayama M, Araie M: Hyperbaric pressure and increased susceptibility to glutamate toxicity in retinal ganglion cells in vitro. Mol Vis 2014;20:606615.

77 Mansouri K, Weinreb RN, Medeiros FA: Is 24-hour intraocular pressure monitoring necessary in glaucoma? Semin Ophthalmol 2013;28:157-164.

78 Leidl MC, Choi CJ, Syed ZA, Melki SA: Intraocular pressure fluctuation and glaucoma progression: what do we know? Br J Ophthalmol 2014;98:1315-1319.

79 Hernandez MR, Pena JD, Selvidge JA, Salvador-Silva M, Yang P: Hydrostatic pressure stimulates synthesis of elastin in cultured optic nerve head astrocytes. Glia 2000;32:122136.

80 Salvador-Silva M, Aoi S, Parker A, Yang P, Pecen P, Hernandez MR: Responses and signaling pathways in human optic nerve head astrocytes exposed to hydrostatic pressure in vitro. Glia 2004;45:364-377. 
81 Mandal A, Shahidullah M, Delamere NA: Hydrostatic pressure-induced release of stored calcium in cultured rat optic nerve head astrocytes. Invest Ophthalmol Vis Sci 2010;51: 3129-3138.

82 Kashiwagi K, lizuka Y, Tanaka Y, Araie M, Suzuki Y, Tsukahara S: Molecular and cellular reactions of retinal ganglion cells and retinal glial cells under centrifugal force loading. Invest Ophthalmol Vis Sci 2004;45:3778-3786.

83 Li A, Zhang X, Zheng D, Ge J, Laties AM, Mitchell CH: Sustained elevation of extracellular ATP in aqueous humor from humans with primary chronic angle-closure glaucoma. Exp Eye Res 2011;93:528-533.
84 Quigley HA, Hohman RM, Addicks EM, Massof RW, Green WR: Morphologic changes in the lamina cribrosa correlated with neural loss in open-angle glaucoma. Am J Ophthalmol 1983;95:673-691.

85 Kirwan RP, Fenerty CH, Crean J, Wordinger RJ, Clark AF, O'Brien CJ: Influence of cyclical mechanical strain on extracellular matrix gene expression in human lamina cribrosa cells in vitro. Mol Vis 2005;11:798-810.

86 Quill B, Docherty NG, Clark AF, O’Brien CJ: The effect of graded cyclic stretching on extracellular matrix-related gene expression profiles in cultured primary human lamina cribrosa cells. Invest Ophthalmol Vis Sci 2011;52:1908-1915.
87 Quill B, Irnaten M, Docherty NG, McElnea EM, Wallace DM, Clark AF, O'Brien CJ: Calcium channel blockade reduces mechanical strain-induced extracellular matrix gene response in lamina cribrosa cells. Br J Ophthalmol 2015;99:1009-1014.

88 Sander EA, Nauman EA: Effects of reduced oxygen and glucose levels on ocular cells in vitro: Implications for tissue models. Cells Tissues Organs 2010;191:141-151.

89 Costa VP, Harris A, Anderson D, Stodtmeister R, Cremasco F, Kergoat H, Lovasik J, Stalmans I, Zeitz O, Lanzl I, Gugleta K, Schmetterer L: Ocular perfusion pressure in glaucoma. Acta Ophthalmol 2014;92:e252-e266. 